\title{
The Benefit Impact of Air Pollution Reduction Through ATCS Implementation at Intersections
}

\author{
Mochamad Arief Budihardjo ${ }^{1 *}$, Haryono Setiyo Huboyo ${ }^{1}$, Budi Prasetyo Samadikun ${ }^{1}$ \\ ${ }^{1}$ Department of Environmental Engineering, Faculty of Engineering, Diponegoro University, Semarang - Indonesia
}

\begin{abstract}
The field study in five intersections that had ATCS, such as Krapyak, Tugu Muda, Polda, Bangkong and Fatmawati were done to investigate the effectivity of air pollution reduction. The study was done by estimating the differences between the vehicle speed due to the cycle duration of green light by field observation and video recording in each intersection. In five intersections that had been observed, the percentage of fuel consumption savings for two-wheeled vehicles were between $15-18 \%$, meanwhile for four-wheel vehicles were between $30-46 \%$. Based on the calculation that adopt the emission factor from CORINAIR and USEPA emission, the emission reduction based on pollutant types were TSP (12-17\%), NOx $(22-36 \%), \mathrm{CO}(15-25 \%), \mathrm{HC}(16-28 \%)$ and SO2 (22-35\%). The result to the vehicles' speed that passed the intersections through ATCS has also indicated that the ATCS could increase vehicle speed and consequently reduce the emission.
\end{abstract}

\section{Introduction}

Nowadays, transportation has become priority for people, mostly for those who live in municipalities. There are various types of transportation, however the most preferred one is road transportation [1]. Similar to other big cities in Indonesia, the demand for road transportation in Semarang has also increased drastically due to economic progression. The number of private cars and motorcycles has grown enormously over public transportations and most of them are powered by combustion engine [2].

As a result of combustion process, the combustion engine will discharge emission. Large amounts of this pollutant will degrade air quality. Highway is one of the largest sources of air pollution emitted from transportation, especially in such complex road systems like road system with the bridge and intersections [3].

Emissions in the highway will disperse to the surrounding areas. This will affect the surrounding environment and increasing the risk of exposure to humans living around the highway. There are about 200 thousand deaths each year due to outdoor pollution that affect urban areas, and about $93 \%$ of cases occur in developing countries [4].

The air pollution generated from transportation mainly consist of $60 \%$ of carbon monoxide and about $15 \%$ consists of hydrocarbons. The most harmful pollutant to health are particles, followed by nitrogen oxides (NOx), sulphur oxides (SOx), hydrocarbons (HC), and the least toxicity is carbon monoxides $\left(\mathrm{CO}_{2}\right)$ [5].

\footnotetext{
Corresponding author: m.budihardjo@ftt.undip.ac.id
}

In most municipalities, main roads and highways are equipped with Area Traffic Control System (ATCS). ATCS is a control system of highway traffic intersection using traffic light (traffic light) where traffic light settings at each intersection coordinated with each other, so that road users get a minimum of delay [3]. With the implementation of an ATCS, there will be efficiency of movement, increasing capacity of the intersection to serve traffic, cutting travel time, decreasing the level of risk of injury to the rider, creating opportunity to provide higher safety for pedestrians and providing better comfort for road users. ATCS very well be applied to the junction point with busy traffic movement and high volume of traffic [6].

Even the implementation of ATCS has some advantages on the traffic, however, the benefit of ATCS on pollution reduction has not been reported yet. Thus, this study aims to investigate the contribution of ATCS on pollution reduction by performing filed investigation at intersections in Semarang City, Indonesia.

\section{Methodologies}

This research was conducted at five intersections in Semarang city i.e Krapyak, Tugu Muda, Polda, Bangkong and Fatmawati from October 2016 to November 2016. Location of research is depicted in Fig. 1. Recorded videos of ATCS (Area Traffic Control System) center were used for observing number and speed of vehicles pass through the intersection. We intensively observed the video during peak hours i. e in the morning from $06.00-10.00 \mathrm{AM}$ and $03.00-06.00$ PM each day. Field validation of speed was conducted for several samples in the surrounding of intersections. 


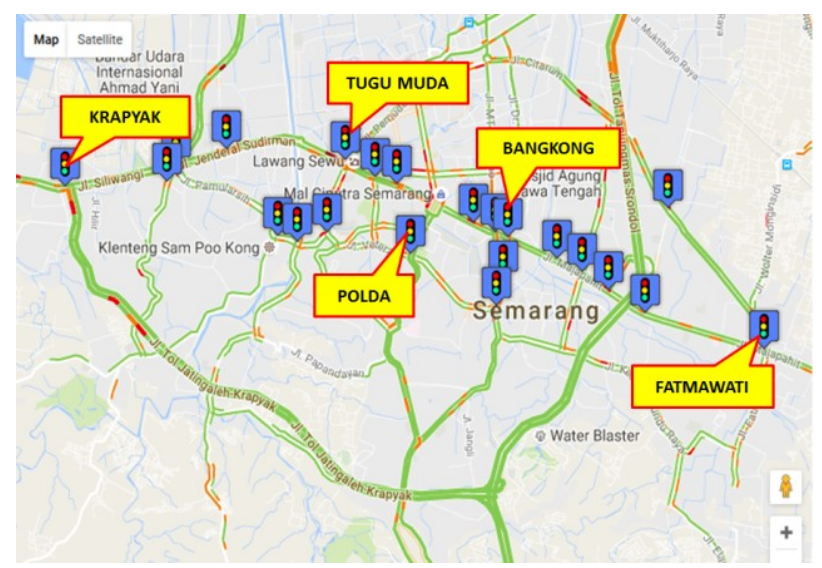

Fig. 1. Location of the Study

At the ATCS center, we record the phase modification i.e changing the duration of green light to accommodate peak vehicles. Thus we were able to know the changing vehicle speed due to changing phase of traffic light.

From each observation we record the vehicle speed, we estimate the emission reduction due to increasing speed. We did not estimate any increasing emission on other intersection lane due to increasing red light. However we assume the increasing on other lane at intersections are much lower than the lane we observed as we our observing lane is the main road (higher road class than other roads in the intersection). For estimating air pollution emission, we adopt SITRAMP (2004) study combining with emission factor derived from IPCC, CORINAIR (2009) and USEPA (1995).

\section{Results and Discussion}

\subsection{Vehicle Characteristics}

The vehicle number during observation at each lane are shown in Table.1. It can be seen that the number of vehicles were varied during observation for the same lane with high vehicles volume in Tugu Muda, Bangkong and Fatmawati. The number of vehicles during green light are much higher than during red light except for Krapyak intersection.

Table 1. Average vehicle volume on observed intersection

\begin{tabular}{|l|c|c|c|l|}
\hline Intersections & \multicolumn{2}{|c|}{$\begin{array}{l}\text { Vehicle number } \\
\text { during green light }\end{array}$} & \multicolumn{2}{c|}{$\begin{array}{l}\text { Vehicle number } \\
\text { during red light }\end{array}$} \\
\cline { 2 - 5 } & $\mathbf{2}$ wheels & $\mathbf{4}$ wheels & Motor & Mobil \\
\hline Krapyak & $67^{*}$ & $32 \pm 9$ & $74 \pm 51$ & $30 \pm 16$ \\
\hline Tugu Muda & $132 \pm 42$ & $45 \pm 18$ & $93 \pm 54$ & $52 \pm 20$ \\
\hline Polda & $54 \pm 18$ & $33 \pm 9$ & $32 \pm 17$ & $23 \pm 12$ \\
\hline Bangkong & $132 \pm 50$ & $36 \pm 9$ & $85 \pm 52$ & $32 \pm 13$ \\
\hline Fatmawati & $139 \pm 45$ & $38 \pm 7$ & $119 \pm 48$ & $25 \pm 14$ \\
\hline
\end{tabular}

* only once observation

Changing phase of operational traffic light by extending duration of green light may increase the vehicle speed as depicted in Fig 2, both for 4 wheels (Fig.2A) and 2 wheels (Fig.2B). This figure illustrate vehicle speed increase as the function of green light duration at Tugu Muda intersection.

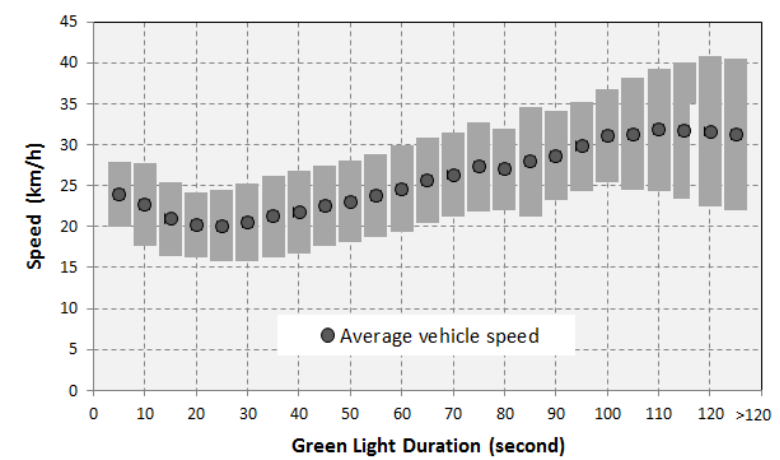

(A)

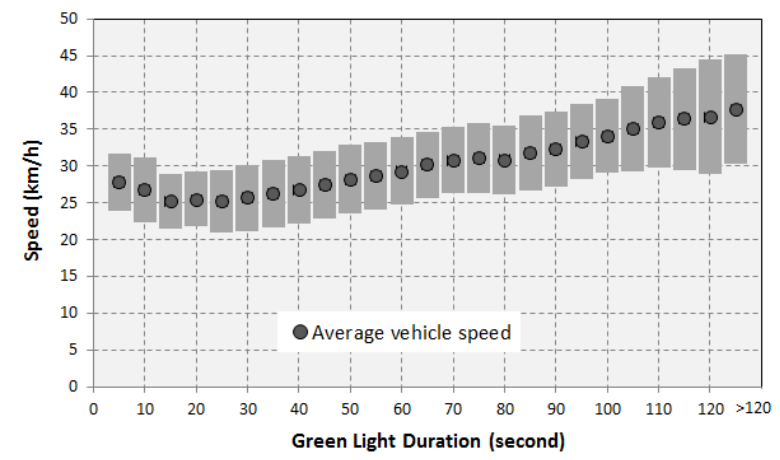

(B)

Fig.2 Increasing vehicle speed, 4 wheels (A) and 2 wheels (B) due to elongated green light duration

\subsection{Emission Reduction}

As the speed of vehicles at the ATCS implementation tend to increase at certain level then it could reduce the emission based on formula of fuel consumption of SITRAMP study [7]. The vehicle speed increase before and after implementation of ATCS could be seen in Figure 3 as follows:

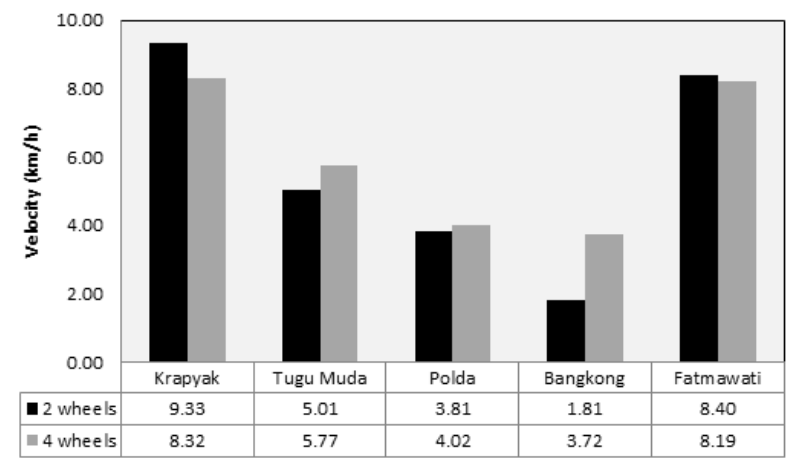

Fig.3 Speed increase due to ATCS implementation

It is obviously, both two wheels and four wheels vehicles had increasing speed because of modification of traffic light operation.

We estimate the emission reduction after ATCS operation in Table 2. Highest emission reduction percentage was performed for NOx parameter, while the lowest emission reduction was shown by TSP parameter. 
This emission reduction is the aggregation of emission reduction of both two wheels and four wheels.

Table 2. Emission Reduction After ATCS Operation

\begin{tabular}{|l|c|c|c|c|c|}
\hline & Krapyak & $\begin{array}{c}\text { Tugu } \\
\text { Muda }\end{array}$ & Polda & Bangkong & Fatmawati \\
\hline TSP & $17.47 \%$ & $15.42 \%$ & $15.05 \%$ & $12.69 \%$ & $15.10 \%$ \\
\hline NOx & $36.78 \%$ & $33.95 \%$ & $34.07 \%$ & $22.81 \%$ & $23.87 \%$ \\
\hline $\mathrm{CO}$ & $25.11 \%$ & $20.98 \%$ & $21.56 \%$ & $15.40 \%$ & $17.07 \%$ \\
\hline $\mathrm{HC}$ & $28.25 \%$ & $23.81 \%$ & $24.59 \%$ & $16.88 \%$ & $18.24 \%$ \\
\hline $\mathrm{SO} 2$ & $35.58 \%$ & $32.24 \%$ & $32.60 \%$ & $21.73 \%$ & $22.72 \%$ \\
\hline
\end{tabular}

It should be noted that the emission reduction we calculate based on operation of ATCS during peak hour where the phase modification in this period was very often.

\section{Conclusion}

The effect of ATCS at five intersections in Semarang City ie. Krapyak, Tugu Muda, Polda, Bangkong and Fatmawati has been studied to investigate the effectiveness of ATCS towards reduction of air pollution. The result showed that the implementation of ATCS has increased the vehicle's speed from 2 to 9 $\mathrm{km} / \mathrm{h}$ and reduced the pollutants emitted by vehicle. The reduction of emission based on pollutant types were TSP (12-17\%), NOx (22-36\%), CO (15-25\%), HC (16-28\%) and SO2 (22-35\%).

This research was funded by DIPA Faculty of Engineering-Diponegoro University No. 172/SK/UN7.3.3/V/2017.

\section{References}

1. W. Wen, Expert Systems with Applications 34, 4 (2008)

2. S.J. Santosa, T. Okuda, and S. Tanaka, CLEANSoil, Air, Water 36, 5-6, (2008)

3. F. Costabile and I. Allegrini, Environmental Modelling \& Software 23, 3 (2008)

4. P.K. Hopke, et al., Science of the Total Environment, 4041 (2008)

5. A.F. Both, Science of the Total Environment 443 (2013).

6. B. Zhou, Vehicular technology conference fall (VTC 2010-Fall) IEEE 72nd (2010)

7. JICA-BAPPENAS, Pacific Consultants International and ALMEC Corporation (2003). 